\title{
Research on the Management Mode of EPC Project of Prefabricated Building Based on BIM Technology
}

\author{
Na Zhao \\ Beijing University of Civil Engineering and Architecture, Beijing, China \\ Email: 534367335@qq.com
}

How to cite this paper: Zhao, N. (2021) Research on the Management Mode of EPC Project of Prefabricated Building Based on BIM Technology. Open Access Library Journal, 8: e7616.

https://doi.org/10.4236/oalib.1107616

Received: June 7, 2021

Accepted: July 9, 2021

Published: July 12, 2021

Copyright $\odot 2021$ by author(s) and Open Access Library Inc.

This work is licensed under the Creative Commons Attribution International License (CC BY 4.0).

http://creativecommons.org/licenses/by/4.0/

\section{(c) (i) Open Access}

\begin{abstract}
Combined with the current situation and existing problems of prefabricated building management, this paper proposes to build an EPC general contracting mode suitable for prefabricated building and applies BIM Technology in the EPC mode to study the whole process information management of prefabricated building design, production, construction, operation and maintenance from four aspects of schedule management, organization management, cost management and information management, The future development trend of BIM Technology in EPC mode is prospectively explored.
\end{abstract}

\section{Subject Areas \\ Project Management}

\section{Keywords}

EPC Project General Contracting Management Mode, Prefabricated Building, BIM Technology

\section{Introduction}

With the development concept of "low-carbon, economic and green" put forward in China, prefabricated building has become a new research hotspot in the field of construction due to its advantages of energy saving and environmental protection, high degree of mechanization, small restriction by climate conditions, short construction period and labor-saving.

The general contracting mode has been implemented in China since the end of the 20th century. In 2016, the ministry of housing and urban-rural develop- 
ment issued several opinions on further promoting the development of general contracting, stipulating that the construction party should take the lead in considering the general contracting mode. At present, EPC mode has been applied to China's water conservancy, electric power, oil and other projects, and there are abundant researches on EPC mode.

The development and research of prefabricated building in developed countries are earlier and more mature. The experience and effect of Japan, Singapore, Germany, the United States, Europe and other developed countries in the field of prefabricated building can be used for reference, such as prefabricated frame system in Japan, shear wall system in Singapore, laminated plate system in Germany, prefabricated wood structure and steel structure in the United States, etc.

Based on the analysis of research status at home and abroad, from the perspective of project management mode, through the research on the relationship among EPC mode, prefabricated building and BIM application in the whole process, this paper combs out the logical relationship among the three objects, and puts forward the construction idea of EPC general contracting management mode suitable for prefabricated building. By using BIM Technology in EPC mode, it realizes prefabricated building design and BIM application Information management of the whole process of production, construction, operation and maintenance, so as to maximize the advantages of prefabricated buildings and promote the healthy and stable development of prefabricated buildings [1].

Through the research, a set of standardized application methods are extracted to help the new management mode and new construction mode of the construction industry and improve the efficiency of construction projects.

\section{Advantages of EPC Mode in Prefabricated Construction Project}

\subsection{Helpful to Realize the Organization of Engineering Construction}

EPC mode is implemented in prefabricated construction projects. The investor only needs to concentrate on completing the expected objectives, functional planning and delivery standards of the project, while the design, manufacturing, assembly, procurement and other engineering implementation work are all completed by the EPC general contractor. The general contractor is fully responsible for the project quality, safety, progress and cost, with clear responsibilities and clear objectives. Around the overall goal of engineering construction, the general contractor takes design as the leading factor, comprehensively coordinates manufacturing and assembly links, and systematically allocates resources (manpower, material resources, funds, etc.); the project participants are in the main position of their respective management systems under the overall coordination of the general contractor. They are all around the management and coordination of the overall goal of the project to achieve the management objectives of their own systems. The parts are subordinate to the overall situation, the stages are subor- 
dinate to the whole process, and the subsystems are subordinate to the large system, so as to realize the high integration of the project construction participants under the overall management of the general contractor, To achieve a high degree of organization of engineering construction [2].

\subsection{Helpful to Realize the Systematization of Engineering Construction}

Prefabricated building is generally composed of four subsystems: architecture, structure, electromechanical and decoration. These four subsystems are not only a complete and independent system, but also a larger system. Each subsystem is fabricated, so is the whole system.EPC project general contracting management is a large system, the management of each link and the management of each subcontract belong to the subsystem of this large system, and the subsystem of each link can be subdivided into several sub-systems [3]. The management objectives of each subsystem constitute the major objectives of the whole project general contracting management. The advantage of EPC mode lies in systematic management. In the product design stage, the manufacturing and assembly links of architecture, structure, mechanical and electrical, decoration subsystems are analyzed as a whole, and the technology and management information of each stage and industry are advanced. The whole process systematic planning is carried out, and the modular coordination, standardized interface, fine reservation and embedment of systematic prefabricated building products are designed, so as to meet the requirements of integrated and systematic design, manufacturing, management and management Assembly requirements, to achieve large-scale manufacturing and efficient lean assembly, to play the comprehensive advantages of prefabricated building [3].

\subsection{Conducive to the Realization of Lean Engineering Construction}

The organizational and systematic characteristics of EPC project general contracting management ensure the integration of architecture, structure, electromechanical and decoration, and the integration of design, manufacturing and assembly. The integrated quality and safety control system ensures the preciseness of the system and the traceability of quality and safety responsibilities. The integrated technology system and management system also avoid the "mistakes and Omissions" in the process of engineering construction, which is inferior to the realization of lean and refined operation [4] in the design stage of assembly construction under EPC mode, the process of manufacturing and assembly, quality control points, support, hoisting and other details in the process of manufacturing and assembly are systematically considered to avoid the risk points of quality and safety from the beginning of design; Through factory manufacturing and on-site mechanized operation, it can greatly replace manual operation, greatly improve the quality of manufacturing and assembly, reduce and avoid the oper- 
ation quality difference caused by the difference of manual skills, and the resulting discreteness is too large, which leads to the quality decline and safety problems, so as to comprehensively improve the project quality Ensure safe production.

\subsection{Beneficial to Reduce the Construction Cost}

In EPC mode, in the design stage, the suppliers of materials, components and subcontractors in the whole process of project construction are determined. With the development of deepening design and technical planning, we can more accurately determine the content and quantity of buyers and sellers in different stages. In this way, the reasonable and large-scale orderly production of subcontractors and material suppliers can be realized, and the centralized production cost, material inventory cost and related indirect cost can be reduced, so as to reduce the procurement cost of the overall material resources of the project. Under the EPC mode, give full play to the advantages of design leading and overall technical planning, fully consider the cost performance of material parts in the design scheme, and give priority to the use of local materials; Cost control in the process of project implementation, through design optimization, to meet the requirements of good performance of construction products at the same time, to save resources to the maximum extent; Through lean design, we can achieve less or even zero design changes, reduce or even avoid the waste of resources caused by rework, so as to maximize cost savings. Under the EPC mode, under the unified coordination and control of the general contractor, the objectives of all parties involved in the construction are unified into the overall objectives of the project, with the lowest overall cost as the goal, which avoids the traditional management mode in which the designer, the manufacturer and the assembly have different interest demands, with their respective interest maximization as the goal, and they do not implement from the perspective of the overall benefit of the project, It leads to the disadvantages of increasing the overall cost and reducing the benefit of the project, so as to reduce the cost. Under the EPC mode, the assembly construction will achieve great labor saving, whether it is the effective integration of the management team or the reduction of industrial workers, it will further reduce the labor cost and indirect cost in the construction process [3].

\subsection{Beneficial to Shorten the Construction Period}

Under the EPC mode, the different links of design, manufacturing, assembly and procurement form reasonable interpenetration and deep integration. The procurement scheme is started only after the original design scheme is determined, and the linear work sequence of manufacturing scheme and assembly scheme is changed into superposition and integration operation. After overall planning, the procurement scheme and assembly scheme are developed at the design stage The production plan, assembly plan and so on, make the follow-up work in ad- 
vance blend, and then greatly save the construction period. Under EPC mode, the original traditional on-site construction is divided into two parts: factory manufacturing and on-site assembly, which can realize the transformation from the original cross flow operation of the same site space to the partial synchronous operation and flow assembly operation of the two spaces, and shorten the whole construction time. At the same time, through the meticulous planning, as well as the mechanized and automatic operation of the factory, the efficient assembly on site can greatly improve the efficiency of production and assembly, and thus greatly save the overall construction period. In EPC mode, the work of all parties is carried out in a unified management and control system, with centralized information sharing, avoiding the problem of poor communication, reducing the workload and time of communication and coordination, thus saving the construction period.

\subsection{Beneficial to Realize Technology Integration Application and Innovation}

EPC mode is conducive to the integration of architecture, structure, mechatronics and decoration, and the integration of design, manufacturing and assembly, so as to realize the technology integration of prefabricated buildings. It can take the benefit of the whole project as the target demand, and clarify the research and development direction of integrated technology. To avoid the problem that it is difficult to study a single technology only from a certain part (such as design technology only, production technology only, and assembly technology only) and to give full play to its advantages. It is necessary to innovate the technology integration of the whole system so as to facilitate the implementation of the technology system, form productivity and give full play to the advantages of the technology system [4].

In the process of EPC general contracting management practice, we should constantly optimize and upgrade the advanced, systematic and scientific technology system, and achieve synergy development of technological non management innovation, so as to improve the construction efficiency.

\subsection{Conducive to the Whole Process Information Application}

EPC mode can give full play to the advantages of BIM Technology in the whole process of information sharing, and improve the quality and efficiency. Under the EPC mode, each participant forms a unified organic whole, sharing data and information between design and industry, manufacturing and assembly, design and manufacturing and assembly, and cooperating in design and management. EPC mode is conducive to the establishment of enterprise level information management platform for the integration of design, manufacturing and assembly of prefabricated buildings, and forms the support for the development of the integration of prefabricated buildings. Realize the deep integration of informatization and non industrialization of construction industry, and further promote the 
application of informatization technology in prefabricated buildings.

\section{Overview of BIM Whole Process Application Research in EPC Mode}

EPC mode, prefabricated building and BIM application are the important contents that our country is vigorously promoting and help to improve the construction level of our country. These three contents provide specific implementation plans and ideas for the transformation and upgrading of the construction industry from the three directions of construction mode, construction mode and building informatization, taking the whole process BIM application content as the final implementation foothold, it reflects the construction process of prefabricated buildings under EPC mode. Through the whole process BIM application (Information Promotion) of prefabricated buildings under EPC mode (management mode), the benefits of construction projects can be improved under the new management mode and new construction mode. Overview of the whole process application research of Bim in assembly building under EPC mode standardized mode is formed through the same BIM model and unified information transmission standard, and integrated management of project information is realized based on construction management platform [5] in the design stage, the coordination of various departments under EPC mode is realized to avoid the problem of "mistakes, omissions and defects". The design management integration realizes the net height optimization, simulation of prefabricated components, buildability analysis, issuance of engineering calculation results, etc., and improves the design quality and design added value through BIM performance analysis. In the construction stage, BIM simulation is used to realize schedule control, quality control, cost control and safety control, so as to reduce resource waste and realize green construction. The completion model after the project completion acceptance establishes a good data foundation for the information and digital management of operation and maintenance [5].

Through the same BIM model and unified information transmission standard, the standardized mode is formed, and the integrated management of project information is realized based on the construction management platform. In the design stage, the requirements of component processing and production are not in front of the construction requirements. In the design stage, the cooperation of various departments is realized under the EPC mode, so as to avoid the problem of "mistakes, omissions and defects". In the design management, the net height is optimized and the components are prefabricated

Through BIM performance-based analysis, the design quality and added value can be improved. In the construction stage, BIM simulation is used to realize schedule control, quality control, cost control and safety control, so as to reduce resource waste and realize green construction. The completion model after the project completion acceptance establishes a good data foundation for the information and digital management of operation and maintenance. 


\section{Overview of BIM Application in Building Life Cycle}

BIM application index of the whole process is the application of Bim in the whole life cycle of buildings, which runs through the planning, design, construction, operation and maintenance, demolition stages of BIM application, especially in the construction process of scheme design, component production, site construction, business management and other aspects. BIM is a way to improve the management of building informatization. It completes the transformation of traditional working mode through various BIM softwares, and takes specific BIM application points and achievements as the main carrier; BIM model is the basis of all BIM applications. BIM model is completed by one specialty, but the integration result of various specialties; BIM itself is not a major, but a way to change the way of work.

\section{Research on BIM Application of EPC Construction Mode}

EPC (engineering procurement construction) mode is the design procurement construction mode, also known as the general contracting mode.EPC is a contract that the general contractor is entrusted by the owner to carry out the whole process or several stages of the design, procurement, construction and trial operation of the construction project according to the contract. Give full play to the leading role of design in the whole process of engineering construction, continuously optimize the overall scheme of engineering project construction, overcome the contradiction of mutual restriction and disjunction among design, procurement and construction, realize the reasonable connection of design, procurement and construction, control the progress, cost and quality of construction project, and conform to the construction contract, Ensure to get better investment benefit. The advantages of BIM are mainly reflected in collaboration, which is highly matched with the collaborative requirements of EPC. Based on the same BIM model, the collaboration of different departments in different specialties and different stages can be realized. From the design stage to the completion and acceptance, the model can support design collaboration, in-depth processing and production of prefabricated components, simulated construction on construction site, and other functions BIM model is used as the only data source for the calculation of business bidding and purchasing quantities [6].

\subsection{Progress Management Based on BIM}

Under the EPC general contracting management mode, the schedule management of prefabricated construction project mainly includes the management of design, production and construction stages. Through BIM Technology, a sharing platform is built to realize the information sharing and communication among participants and specialties in each stage of the project and form dynamic schedule control.

In the design stage, the collision detection function of BIM can be used to find the problems in the design in advance and optimize the engineering design 
scheme. It can avoid the delay of project progress in the production and assembly construction stage due to design problems, which makes the progress management more comprehensive and efficient.

Component production stage. Component manufacturers can obtain the production data information of the prefabricated components required by the project from BIM information sharing platform, so as to control the component production more accurately. On the BIM information sharing platform, the general contractor can pay attention to the production progress of prefabricated components at any time, judge whether the current production progress has an impact on the construction in the subsequent stage, and if it has an impact, timely transmit the results to the manufacturer.

Construction stage. In this stage, the construction unit can use BIM Technology to simulate the real construction environment and construction process. Through the observation model, the construction personnel can timely judge whether the hoisting process meets the requirements of hoisting specifications, whether the project site layout and construction arrangement are reasonable, etc.

\subsection{Organization Management Based on BIM}

The reasonable setting of an organization is to ensure that each department within the organization has a clear division of labor and responsibilities.

In the design stage, combined with the characteristics of prefabricated construction project, EPC general contractor constructs BIM information center and is responsible for the operation and maintenance of BIM information center. The professional personnel in charge of the project design will transfer their data to BIM information platform, and the general contractor will review whether the design results meet the expected requirements of the owner. At the same time, the general contractor should give full play to its leading role and organize the technical leaders in the component production stage and assembly construction stage to participate in the preliminary design; In this stage, BIM Technology is used to build three-dimensional model, and the collision in design can be found in time in the virtual environment, so as to avoid the production or assembly conflict caused by design errors.

In the production stage, as the bridge of design and construction, the quality of prefabricated components produced in the production stage is directly related to the overall quality of prefabricated construction project, so this stage is the key link of quality control. Manufacturers can learn the information of the prefabricated components to be produced from BIM information sharing platform, and then prepare the component production plan for mass production. At the same time, in this stage, the general contractor should give full play to the leading role, organize and mobilize the designers to supervise and manage whether the relevant component splitting of prefabricated construction project meets the requirements of design specifications.

In the construction stage, the general contractor can use BIM Technology to 
simulate the real construction environment and construction process, predict whether there are construction collisions and design defects, and then effectively organize people, talents and machines to intersperse construction according to the plan, so that all processes can be orderly overlapped. At the same time, the general contractor shall give full play to the leading role, mobilize the designers and production technicians to the site to assist in the construction and installation, and supervise and manage the site work [6].

\subsection{Cost Management Based on BIM}

In order to reduce the construction cost of prefabricated building, EPC general contracting mode is applied to manage the prefabricated building, and the whole process cost control of the prefabricated building project is carried out as a whole.

Design phase. Construction drawing design, splitting design and detailed design are the main work contents in this stage. On the basis of fully considering the production and assembly construction of prefabricated components, the design scheme should be optimized as far as possible, the connection nodes should be standardized, the splitting design should be optimized, and the types and specifications of components should be reduced, so as to reduce the manufacturing cost and turnover cost of multi specification of prefabricated components.

Production stage. In the production stage, the manufacturer should strictly follow the design drawings, prefabrication scheme and relevant quality specifications for production. The production quality points must be strictly controlled to prevent the rework of prefabricated components due to unqualified production quality, resulting in low production efficiency and additional cost increase.

Construction and installation stage. The construction stage of prefabricated building is not only the stage of forming building entity, but also the stage of consuming a lot of human, financial and material resources. Because the construction in this stage often has the characteristics of long time and many uncontrollable factors, the cost control in the construction stage is the key and difficult point of project management. In this stage, the construction party should prepare a specific plan for the use of cost, and carry out the construction in strict accordance with the plan; at the same time, the construction party should combine with the characteristics of prefabricated buildings and try to improve the quality of buildings.

\subsection{BIM Based Information Management}

Prefabricated construction projects experience four stages: design, production, construction, operation and maintenance, and the work in each stage are complicated. As the EPC general contractor, it is necessary to manage the whole construction process as a whole, coordinate and handle the relationship between each stage and each participant, and ensure the timely circulation and sharing of project information in each stage and each participant. The general contractor uses BIM Technology to create BIM information sharing platform. The general contractor 
is responsible for integrating BIM information center with all data information of the project, including data information of all stages, key indicators, organizations and specialties of the project. At the same time, the general contractor uses the integrated information to coordinate the design of various disciplines, eliminate conflicts by collision detection, carry out production and construction simulation, open up the whole industry chain, and realize dynamic control of schedule control and cost control. The establishment of BIM information sharing platform greatly improves the efficiency of communication management, reduces the probability of project loss due to information asymmetry, and finally achieves the purpose of improving the overall efficiency of prefabricated construction projects.

\section{The Future Development Trend of BIM Application in EPC Mode}

\subsection{Collaborative Operation of All Parties Based on Cloud Computing}

Cloud computing is a computing method based on the Internet. The software, hardware and information resources shared in this way can be used by computers and other terminals according to the demand.

\subsection{Building Big Data Analysis Based on BIM Model to Enhance the Value of Digital Assets}

BIM integrates all kinds of information in the whole life cycle of buildings, and the fundamental of big data analysis is data. Big data analysis of construction industry based on BIM model is based on BIM cloud platform at provincial or national level, integrating regional or national building models for information data processing and algorithm analysis, which can plug in the development status of construction industry from the macro perspective, and effectively control construction quality, cost and duration from the perspective of macro-control.

\subsection{BIM Model Combined with Digital Virtual Reality to Control Project Construction Quality in an All-Round Way}

The idea of BIM Technology is to establish a model information base covering the whole life cycle of construction engineering, and to realize the model-based information integration and sharing among different specialties in each stage. BIM is not an integrated application of virtual reality technology. Its main contents include virtual scene construction, construction schedule simulation, complex local construction scheme simulation, construction cost simulation, multi-dimensional model information joint simulation and interactive scene roaming. The purpose is to better apply virtual reality technology in the whole life cycle of construction projects.

\subsection{Lean Construction and Intelligent Construction Based on BIM}

Lean construction and intelligent construction based on BIM refer to the organic 
combination of BIM software and hardware to improve the construction accuracy of the project, such as the production of BIM + digital processing butt assembled components, the lofting and deformation observation of BIM + Intelligent Total Station, BIM + 3D scanning and BIM + 3D printing, etc.

\section{Countermeasures and Suggestions on Promoting the Development of EPC Management of Prefabricated Building}

2016 Since, under the guidance of national policy, the pace of prefabricated building development in China has been fully accelerated, and the sunrise of large-scale development of prefabricated building has been rising. In this context, it is more urgent to promote the EPC project management of prefabricated construction.

Establish a supporting industry management system and mechanism. The first is to accelerate the improvement of EPC project bidding management system, strengthen the project contracting management of construction units, further clarify the responsibilities and obligations of EPC enterprises, improve the risk management and quality and safety supervision of EPC projects, and strengthen subcontracting management. The second is to establish a work coordination mechanism, strengthen the communication and coordination between relevant departments of EPC project construction, and actively solve the system and mechanism problems that restrict the implementation of EPC project.

Constantly improve the management level of general contracting of enterprises. The strategic positioning of EPC enterprises should be intelligence intensive and technology intensive enterprises, and it is necessary to build the organizational structure and management system matching with its development strategy. It is simply transformed from design institute + production enterprise + assembly enterprise.

It is difficult to meet the goal of integrated management for the general contracting enterprises. EPC project general contracting management is not a simple superposition of design work, production work, assembly work and procurement work in the general sense. It breaks through the project level and rises to the business operation and development strategy level of EPC project.

Therefore, EPC mode pays more attention to the connotation and essence of management, emphasizes the use of the integration and coordination ability of the general contractor, the mastery of market resources and the management ability of the sub contractors to achieve integrated management, so as to add value to the project and obtain greater benefits.

On the basis of strengthening technological innovation, we should pay attention to management innovation. One is the integrated technology system.EPC mode pays more attention to design pilot, through the design to factory manufacturing, field assembly, and later operation and maintenance. Adhere to the design concept of standardization, integration and systematization, through the overall analysis of the design scheme, manufacturing process and assembly me- 
thod of architecture, structure, electromechanical and decoration subsystems form a perfect and detailed design scheme. At the same time, we must synchronously innovate the automatic manufacturing technology of factory production equipment system linkage, and the on-site standardization and process oriented mechanical efficient assembly technology, constantly optimize and upgrade the integrated technical standards, and ensure the advanced and systematic nature of the technical system.

The second is management innovation. The management innovation of EPC project general contracting should adapt to the technology system, and cooperate with the integrated technology system for innovation and development. Through the EPC project general contracting management, the advantages of the overall technology system should be brought into play, and the core competitiveness of enterprise technology system and management system should be built.

Third, information management technology. It is necessary to actively promote the application of advanced and practical engineering project information management technology, establish an information management platform suitable for EPC project general contracting management, and improve the efficiency and benefit of project management, focusing on the establishment of an information management platform combining BIM-ERP for prefabricated buildings; The whole process collaborative design based on BIM Technology is established; Building BIM family library of assembly building in the whole process; Research the technology of factory automation production and information management based on BIM cam and MES; Research the whole process of $5 \mathrm{~d}$-bim information assembly management.

Speed up the talent cultivation of EPC project general contracting. From the perspective of the whole industry chain, according to the prefabricated building technology system and management mode, we should actively cultivate and allocate the composite talents related to the prefabricated building, which integrates design processing assembly and EPC project management. First, we should speed up the formulation of the basic requirements for the project manager of the EPC project of prefabricated construction; Second, the government, universities and construction enterprises should form a joint force, increase the targeted vocational education, and do a good job in improving the ability and quality of EPC project general contracting management team and the professional skills of construction workers.

Strengthen the cultivation and guidance of leading enterprises. The core of prefabricated building is the change of production mode, which will bring impact on the current traditional development mode. Therefore, a series of changes will take place in the whole construction industry, facing a new round of reform and development. It is urgent for the industry to cultivate a number of leading enterprises with strong technical strength and competitiveness for the development of prefabricated buildings. It is necessary to gradually clarify the responsibility subject and leading position of these leading enterprises in batches, and 
give full play to their overall integration ability. Combined with engineering practice, it is necessary to explore and innovate EPC project general contracting management, drive the integrated development of prefabricated building related industries, and realize the socialized mass production and industrial development of prefabricated buildings.

\section{Conclusion}

With the gradual development of new information technology and engineering management concept, prefabricated building, because of its advantages of energy-saving, environmental protection and high efficiency, has better solved a series of disadvantages of traditional cast-in-place construction engineering management mode, such as long construction period, poor environmental protection benefit, many safety hazards and low industrial production efficiency. The application of EPC mode in prefabricated construction project management can effectively shorten the construction period, reduce the construction cost and maximize the construction benefit. At the same time, the introduction of BIM Technology into the EPC general contracting management mode can achieve the goal of standardized component design, reduce error, optimize the quantity statistics and cost management, improve the efficiency of communication and management, further promote the development of prefabricated buildings, and become an important trend of the future development of the construction industry.

\section{Conflicts of Interest}

The author declares no conflicts of interest.

\section{References}

[1] Meng, X.B. (2021) Research on Improvement of EPC Project Management Capability. Low Carbon World, 11, 301-302.

[2] Li, W. (2021) Application Practice of Green Construction of Prefabricated Buildings Based on BIM. Green Environmental Protection Building Materials, 5, 21-22.

[3] Liang, X.C. (2020) Quality Management System and Strategy of Assembly Construction Engineering under EPC Mode. Construction Economy, 41, 73-78.

[4] Qiu, S.Y. (2020) Application of BIM Technology in EPC Mode PC Building. Master's Thesis, Jiangsu University of Science and Technology, Zhenjiang.

[5] Zhou, L.N. (2019) Analysis of BIM Technology Collaborative Prefabricated Building Construction Mode under EPC Mode. Taiwan Science and Technology and Industry, 12, 41-43.

[6] Wu, R.Z. (2020) Discussion on EPC and Project Management of Prefabricated Building. Quality and Market, 258, 80-82. 